\title{
La asamblea general comunitaria de Oxchuc como modelo de gestión electoral en escenarios de diversidad cultural
}

\author{
The Oxchuc community general assembly as a model of electoral management \\ in cultural diversity scenarios
}

\section{Manuel Gustavo Ocampo Muñoa (iD \\ Universidad Autónoma de Chiapas, México}

\begin{abstract}
RESUMEN El presente documento pretende establecer la importancia que para la sociedad de Oxchuc reviste el legitimar la autoridad municipal mediante un nuevo modelo de elección de autoridades, que excluye el sistema de partidos políticos y posiciona la asamblea general comunitaria como órgano de gestión electoral. A partir de sus decisiones, se construye una alternativa de participación ciudadana en escenarios de diversidad cultural.
\end{abstract}

PALABRAS CLAVE Modelo de gestión, derecho electoral, asamblea, pueblo originario.

\begin{abstract}
This document intends to establish the importance for the Oxchuc society of legitimizing the municipal authority through a new model of election of authorities that excludes the system of political parties and positions the general community assembly as an electoral management body. From their decisions, an alternative of citizen participation in cultural diversity scenarios is built.
\end{abstract}

KEYWORDS Management model, electoral law, assembly, native people.

\section{Introducción}

En lengua tseltal, la palabra oxchuc significa «tres nudos», de acuerdo con la tradición oral de ese municipio indígena chiapaneco. Deriva de la siguiente historia: existía un demonio denominado Topinsil (dios del inframundo del pueblo tseltal) que molestaba al pueblo; ante tal situación, santo Tomás - quien es el santo patrono del pueblo- decidió poner paz. Para ello, emborrachó al demonio con posh (una bebida alcohólica elaborada a partir del maíz) y lo amarró en uno de los cerros de Oxchuc, dándole tres vueltas con una cadena. De ahí deriva la expresión «tres nudos». 
Este pueblo tseltal es descendiente de los mayas y se instaló en las tierras del actual municipio de Oxchuc antes de la llegada de los conquistadores españoles. A mediados del siglo XVI, los misioneros españoles, encargados de la evangelización de la zona, dieron al pueblo las bases de un gobierno colonial. Es uno de los municipios tseltales más antiguos de Chiapas, y cuenta con una densidad de población superior a los 50 habitantes por kilómetro cuadrado (Gómez Muñoz, 2004). Se localiza entre el altiplano central y las montañas del Norte, en el estado de Chiapas.

En 1950, la asamblea general comunitaria única se estableció por primera vez en Oxchuc para elegir a Sebastián López Ch’ijk como su primer presidente municipal tseltal, ya que antes solo los mestizos eran tanto los electores como los elegidos. El método electoral de partidos políticos que aparece desde la institucionalidad del Estado nación como un régimen obligatorio, ha sido en todo momento violatorio a los derechos de autodeterminación de los pueblos indígenas, debido a que promueve el divisionismo al interior de las comunidades, y genera escenarios de corrupción y violencia que impactan en la legitimidad de las autoridades locales. Los partidos políticos se convierten en impulsores de prácticas que contravienen la libre toma de decisiones políticas al interior de los pueblos originarios.

En el presente documento se pretende establecer la importancia que para la sociedad de Oxchuc reviste el legitimar la autoridad municipal mediante un nuevo modelo de elección de autoridades, que excluye el sistema de partidos políticos y posiciona la asamblea general comunitaria como órgano de gestión electoral. A partir de sus decisiones, se construye una alternativa de participación ciudadana en escenarios de diversidad cultural.

El artículo se divide en seis secciones. En el apartado "¿Por qué diseñar un nuevo modelo de gestión electoral y participación ciudadana en Oxchuc?», se justifica el diseño de un modelo de elección diferente al establecido por el sistema electoral mexicano en Oxchuc. Luego, al exponer el marco teórico, se describen algunos conceptos que impactan directamente en la construcción de un modelo de electoral, como son la interlegalidad y los sistemas normativos internos.

Al analizar el Tribunal Electoral del Poder Judicial de la Federación (TEPJF) y la crisis política en Oxchuc, se describe la problemática generada en el municipio indígena producto de la lucha por el poder que se desata entre los partidos políticos. Así también se reflexiona acerca del papel del TEPJF en la judicialización del derecho a la libre determinación en materia electoral.

En el ejercicio del derecho a la consulta se narra el proceso llevado a cabo por el Instituto de Elecciones y Participación Ciudadana de Chiapas (IEPC) para organizar la asamblea general única, que se constituyó en el órgano electoral en este nuevo esquema de participación política.

$\mathrm{Al}$ referirnos a las reglas de la elección por sistemas normativos internos, se revisa lo acontecido en Oxchuc y su influencia en otros pueblos y comunidades de Chiapas en cuanto a procesos autonómicos y de coexistencia entre el derecho estatal y el derecho indígena. Por último, se establecen las reflexiones finales del tema. 


\section{¿Por qué diseñar un nuevo modelo de gestión electoral en Oxchuc?}

En el municipio de Oxchuc la lucha por el control político en los últimos veinte años involucra a profesionistas indígenas, quienes dejaron el pueblo durante un buen tiempo y regresan para buscar un espacio de poder. Desafortunadamente, la dinámica utilizada por este grupo se ha caracterizado por actos de violencia hacia las personas que integran el ayuntamiento, en especial al presidente en funciones, e incluso a su patrimonio y el de sus familiares. De igual manera, se enfoca en la destrucción del patrimonio del ayuntamiento, así como también en la irrupción violenta durante la celebración de los plebiscitos, lo que lleva a veces a la muerte de participantes; en la exclusión radical de sus opositores de los espacios del ayuntamiento; en diversos actos de corrupción relacionados con el saqueo de las arcas públicas; en políticas sociales clientelares; y, por último, en la imposición de agentes y comités municipales en las comunidades afines al presidente municipal en turno. ${ }^{1}$

Esta pugna se agudizó con la intromisión de los partidos políticos en los sistemas internos de elección de autoridades en Oxchuc, mediante prácticas desleales como la compra de votos y la imposición de candidatos y candidatas. Aunado a esto, desde 1999 la contienda se ha centrado entre dos familias que, abanderadas por diferentes partidos, han dividido al pueblo: una se integra por los hermanos Santiz Gómez (Miguel, Jaime, Roberto y Teófilo) y la otra por los hermanos Rogelio y Norberto Santiz López, más la esposa de este último, María Gloria Sánchez Gómez. Ambas familias, en su oportunidad de ocupar el poder, lo han ejercitado bajo escándalos de corrupción caracterizados por la impunidad, la utilización indebida de los recursos públicos y el control de los medios de comunicación.

Ante la falta de legitimidad de los candidatos de los partidos políticos, en 2015 la sociedad civil de este municipio indígena promovió ante las autoridades electorales, mediante organizaciones como el concejo municipal de Oxchuc, y en ejercicio del derecho a la libre determinación en materia política, la celebración bajo su propio sistema normativo de la elección de sus autoridades municipales, argumentando que los partidos políticos han fraccionado a la sociedad y obtenido beneficios ilícitos. En otras palabras, se pretendió renovar la asamblea general comunitaria como la institución encargada de la toma de decisiones en materia electoral.

Lo anterior se concretó en la resolución emitida en el juicio por la protección de los derechos políticos ante el Tribunal Electoral del Estado de Chiapas (TEECH), en la que se vinculó a diferentes autoridades a efecto de respetar el derecho del pueblo de Oxchuc, junto con hacer los estudios y tomar las medidas pertinentes para verificar si el deseo de implementación de dicho sistema electoral era una petición de la mayoría.

1. Araceli Burguete Cal y Mayor, «¿Por qué es conveniente una elección de usos y costumbres en Oxchuc?», Chiapas Paralelo, 22 de febrero de 2016, disponible en http://bit.ly/2QC6E12. 


\section{Marco teórico}

Para entender los alcances de la gestión electoral en escenarios de diversidad cultural, es imprescindible conocer algunos conceptos que sirven de guía en este trabajo.

El primero es el de interlegalidad, que parte de la existencia de una constante intersección de diferentes órdenes legales, como consecuencia de que múltiples ordenes normativos regulan al mismo tiempo las mismas conductas (Santos, 1987). Por lo tanto, la construcción de un concepto de derecho debe ser lo más amplio posible, para abarcar diferentes expresiones de derecho en tiempo y espacio, pero lo suficientemente compacta para que no pierda su valor heurístico y se trivialice (Santos, 2009).

Desde la interlegalidad, un sistema normativo interno como el de los pueblos originarios reúne poder, derecho y conocimiento, lo que crea un todo armónico dentro de una sociedad determinada, una especie de constelación (Santos, 2001). El pluralismo legal o interlegalidad deja a un lado la mera coexistencia de diferentes sistemas normativos en un mismo espacio político, y se orienta hacia el análisis de la existencia de diferentes espacios legales superpuestos, interpenetrados y mezclados en nuestras mentes tanto como en nuestras acciones legales (Santos, 1987).

La interlegalidad es una intersección de diferentes órdenes legales en los que existe una relación entre el pluralismo jurídico y el pluralismo cultural, que en sociedades que han pasado por procesos de colonización, como las latinoamericanas, son más dicientes, debido a que en un espacio determinado se hallan distintas culturas con su propia teoría del derecho y pluralismo jurídico, con sus respectivas prácticas jurídicas o regulativas.

El sistema normativo interno se identifica como el conjunto de normas jurídicas orales y consuetudinarias que los pueblos y comunidades indígenas asumen como válidas y obligatorias, que utilizan para regular su vida pública y resolver los conflictos.

Desde la concepción defendida de la identidad indígena como relacional, contextual y dinámica, el orden jurídico indígena se define como lo que los propios indígenas reconocen como su gobierno, justicia, sus autoridades, sus normas, sus procedimientos e instituciones (Yrigoyen Fajardo, 1999).

Por su parte, el derecho electoral indígena se integra por el conjunto de leyes y procedimientos propios vigentes que rigen el nombramiento de las autoridades comunitarias, a partir de premisas diferentes de las que sustentan el sistema de partidos políticos. Por ejemplo, el sentido de pertenencia a una comunidad es muy profundo: quienes pertenecen a una comunidad indígena tienen obligaciones comunitarias que, al ser cumplidas, permiten su permanencia en ella (Servicios del Pueblo Mixe, 1995).

La idea de la pertenencia a una comunidad se basa en una visión colectiva y de un desarrollo comunal de la vida. Lo anterior es muy diferente al concepto occidental de la ciudadanía, cuyo enfoque es el individuo. La mentalidad colectivista es el elemento a partir del cual las sociedades originarias han dado forma a su estructura y organización en distintos momentos de su historia (Maldonado Alvarado, 2013). 


\section{El Tribunal Electoral del Poder Judicial de la Federación y la crisis política en Oxchuc}

A pesar del reconocimiento de los derechos colectivos económicos, políticos y culturales de los pueblos originarios, así como la ratificación de tratados de derechos humanos que se integraron al bloque de constitucionalidad (es decir, al conjunto de normas que tienen jerarquía constitucional en el ordenamiento jurídico), los mecanismos institucionales respectivos resultaron insuficientes para hacerlos efectivos, ya sea por falta de técnica legislativa o por razones de control político. ${ }^{2}$

En el caso del derecho electoral de Oxchuc, existen procedimientos internos bien definidos para elegir a sus autoridades, mismos que hasta antes de la aparición de los partidos políticos se utilizaban en forma eficiente, y cuyo ejercicio mantuvo la paz en los pueblos y comunidades. Se trataba de un sistema de elección incluyente que tomaba en consideración a las autoridades tradicionales, a las comunidades y a los principales, por lo que repartía el poder en la conformación de la autoridad municipal. Desafortunadamente, al momento de incorporar la libre determinación en materia política como derecho colectivo de los pueblos indígenas en el ordenamiento constitucional, ellos ganaron el reconocimiento estatal, pero perdieron la unidad al interior de la comunidad.

Las actuaciones del TEPJF respecto del conflicto político de Oxchuc se documentan sobre todo a partir de la controversia planteada en el juicio SUP-JDC-1756/2016, del 17 de agosto de 2016, promovido por María Gloria Sánchez Gómez per saltum ante la Sala Superior del Tribunal.

En la demanda se advierte que el 4 de febrero del mismo año, la referida ciudadana presentó ante el Congreso del estado de Chiapas una licencia al cargo de presidenta municipal de Oxchuc, la cual fue calificada como renuncia por el Congreso del estado mediante Decreto 161, del 11 de febrero. El 24 de junio, Sánchez Gómez presentó un oficio dirigido al presidente de la Mesa Directiva del citado órgano legislativo, en el que se solicitó su reincorporación al cargo. El 14 de julio, presentó un nuevo escrito ante la misma autoridad, en el que solicitó que a la brevedad se pronunciara sobre lo peticionado. El 2 de agosto le fue notificado el Oficio 327, suscrito por la secretaria de la Comisión Permanente del Congreso del estado de Chiapas, en el cual se le notificó que no era posible reincorporarla al cargo, toda vez que, mediante el Decreto 161, su licencia fue calificada como renuncia.

Inconforme con lo anterior, el 8 de agosto Sánchez Gómez presentó una demanda para la protección de los derechos políticos y electorales del ciudadano ante el TEECH. Al entrar al estudio del asunto, la Sala Superior del TEPJF consideró válido afirmar que, con motivo de la elección celebrada en julio de 2015, se desató un conflicto social y político que derivó en diversos hechos violentos que han tenido repercusión en todo el

2. Manuel Eduardo Góngora Mera, «El bloque de constitucionalidad en Argentina y su relevancia en la lucha contra la impunidad», Centro de Derechos Humanos de Núremberg, 9 de enero de 2007, disponible en https://bit.ly/2Tjy8Ku. 
municipio, lo que llevó a María Gloria Sánchez Gómez a presentar licencia por tiempo indefinido ante el Congreso del estado el 4 de febrero. A juicio de la autoridad resolutora, es evidente que las presiones y la violencia política probada colocó a la presidenta municipal en una situación de mayor vulnerabilidad, lo que la orilló a presentar su licencia. Se acredita que, a lo largo de los primeros seis meses de ejercicio del cabildo constitucionalmente electo, se presentaron situaciones de violencia, conflicto social y atentados contra el órgano de gobierno municipal, los que impidieron el normal desarrollo de las funciones del ayuntamiento, protestas que se centraron en la destitución de María Gloria Sánchez Gómez en el cargo en la presidencia municipal.

En síntesis, la resolución del 31 de agosto de 2016 revocó el Decreto 161 emitido por el Congreso del estado de Chiapas, así como el oficio emitido por la Secretaría de la Comisión Permanente del propio Congreso local, a través del cual se negó a María Gloria Sánchez Gómez su reincorporación al cargo de presidenta municipal. Además, dejó sin efectos los Decretos 174 y 178, mediante los cuales se nombró a Óscar Gómez López como presidente municipal sustituto y a Obidio López Santiz, Manuel Gómes Rodrígues y Juan Santiz Rodríguez como regidores sustitutos de representación proporcional.

De igual manera, vinculó a la Secretaría General del gobierno del estado y al Congreso del estado de Chiapas para que, a través del diálogo y la concertación, de manera oportuna, adecuada y eficaz, crearan los cauces institucionales para sensibilizar a las partes en conflicto a efecto de que colaboren en el cumplimiento del fallo del TEPJF.

El 11 noviembre del 2016, la organización denominada Comisión Permanente por la Paz y Justicia del Municipio de Oxchuc, Chiapas, presentó un escrito ante el Instituto de Elecciones y Participación Ciudadana (IEPC), en el que solicitaba autorización para celebrar la elección de sus autoridades municipales a través de su sistema normativo propio.

En enero de 2017 , cerca de 28.000 pobladores de Oxchuc, encabezados por autoridades comunitarias y tradicionales, firmaron una petición dirigida al IEPC solicitando que las elecciones municipales del proceso 2018 se hicieran sin la participación de partidos políticos; es decir, mediante el sistema normativo interno.

El 10 de febrero de 2017, a propuesta de la Comisión Permanente de Participación Ciudadana del Consejo General del IEPC, se emitió el Acuerdo IEPC/CG-005/2007, mediante el cual se determinó que no son procedentes las peticiones planteadas por la Comisión Permanente por la Paz, de celebrar elecciones a través del sistema normativo de usos y costumbres del municipio de Oxchuc. Ante la incompetencia que argumentó el IEPC para autorizar elecciones - pues era competencia del legislador-, la Comisión Permanente por la Paz promovió un juicio para la protección de los derechos políticos electorales del ciudadano.

El 8 de marzo de 2017 un grupo de ciudadanos y organizaciones presentaron escritos de promoción de juicios para la protección de derechos políticos electorales del ciudadano ante la Sala Superior del TEPJF, vía per saltum. El 4 de abril de 2017, dicha autoridad determinó declarar improcedentes los juicios ciudadanos y, en consecuencia, ordenó reencauzarlos al TEECH para que resuelva. 
El 28 de junio del 2017, el TEECH resolvió el expediente TEECH/JDC/o19/2017 y sus acumulados, ${ }^{3}$ mediante sentencia definitiva, en el que ordena al IEPC ejecutar varias acciones para determinar la viabilidad de la implementación de los usos y costumbres en este municipio y que, de ese modo, puedan elegir a sus representantes dentro del ayuntamiento municipal sin participación de partidos políticos.

Aunque la sentencia definitiva del expediente TEECH/JDC/o19/2017 estableció una serie de actividades a ejecutar por el IEPC, la preparación del proceso electoral ordinario 2018 exigía mayor atención, por lo que el Congreso del estado de Chiapas emitió el 2 de abril un decreto que autorizaba al IEPC a modificar las fechas y procedimientos en lo tocante a Oxchuc, hasta que concluyera el período de consulta; en consecuencia, no se celebraron elecciones locales en el municipio, sino solo las de carácter federal.

\section{El ejercicio del derecho a la consulta}

Al terminar de manera oficial el proceso electoral local del año 2018, se reanudaron los trámites. El 19 de septiembre de ese año, el IEPC recibió el dictamen antropológico denominado «Sistema normativo indígena para la designación de autoridades en el municipio de Santo Tomás, Oxchuc», publicado por el Instituto Nacional de Antropología e Historia (INAH), el cual concluyó que el sistema normativo interno que regula las formas de gobierno indígena en el municipio de Oxchuc mantiene su vigencia y particularidades. Además, concluyó que si bien el sistema no es discordante con el marco constitucional de los derechos humanos, requiere adaptarse a fin de fortalecer la incorporación de las mujeres y los jóvenes.

En consecuencia, se procedió a organizar la consulta para que los ciudadanos del municipio decidieran sobre qué sistema elegirían a sus autoridades municipales: si por partidos políticos o por usos y costumbres. Lo anterior bajo los estándares internacionales de consentimiento libre, previo, informado y de buena fe que son base del Convenio 169 de la OIT. ${ }^{4}$

Las asambleas de consulta indígena fueron convocadas en las 120 comunidades de Oxchuc. El porcentaje de participación alcanzado fue de $97 \%$, debido a que en las localidades de El Pozo, Navil, Stenlej Akil y Cruz Akilja no se obtuvo el quórum requerido en las tres convocatorias para celebrar sus asambleas comunitarias de consulta indígena. Por ello, de conformidad con los lineamientos, no fueron considerados para la obtención del resultado, participación que dentro de la consulta equivale al $3 \%$.

El 5 de enero de 2019 se celebró la asamblea plenaria de resultados, en la que la ciudadanía de Oxchuc decidió por el sistema normativo interno para elegir a sus autoridades municipales. Según los resultados, 72 localidades optaron por el sistema de

\footnotetext{
3. La sentencia del expediente TEECH/JDC/019/2017 y acumulados promovidos por Sara Gómez Méndez y otros, en juicio para la protección de los derechos políticos electorales del ciudadano, puede consultarse en https://bit.ly/36HCgbi.

4. Araceli Burguete Cal y Mayor, «Elecciones por usos y costumbres en Oxchuc: Los desafíos», Chiapas Paralelo, 11 de enero de 2019, disponible en http://bit.ly/2Nc1Jlc.
} 
usos y costumbres, que en su conjunto representa el $62 \%$, mientras que 44 localidades decidieron por partidos políticos, lo que representa el $38 \%$ de las 116 localidades en las que se hicieron asambleas comunitarias de consulta indígena.

Ahora bien, el objetivo de la asamblea fue dar a conocer a la ciudadanía del municipio, a través de sus representantes, el resultado de su voluntad, plasmada en cada una de las actas de asamblea comunitaria de consulta celebradas, respecto del sistema de elección de sus autoridades municipales por el que optaron. El 15 de enero del 2019, el consejo general del IEPC declaró la validez, en sesión pública, de los resultados de la asamblea plenaria. En virtud de lo anterior, el 23 de enero de 2019 el Congreso del estado de Chiapas emitió el Decreto 135, por el que se faculta al IEPC para convocar, coadyuvar y, en su caso, organizar la elección de autoridades municipales del municipio de Oxchuc, Chiapas, así como calificar y expedir la constancia de mayoría a través del régimen de elección por sistema normativo interno.

En cumplimiento de lo anterior, el IEPC elaboró los lineamientos a seguir y calendarizó las actividades del proceso de elección de autoridades municipales en Oxchuc bajo el sistema normativo de usos y costumbres, que comprendía la celebración de mesas de trabajo, con la finalidad de elaborar la convocatoria e involucrar a los grupos de ciudadanos de Oxchuc, de tal forma que fueran ellos quienes establecieran los criterios del proceso electoral, las reglas y los perfiles de elegibilidad para determinar quiénes podrían ser candidatos, además del procedimiento de elección.

Por acuerdo IEPC/CG-A/o07/2019 del 11 de febrero de 2019, se aprobó la convocatoria a la ciudadanía del municipio para integrar la asamblea general, que se constituyó como la máxima autoridad de deliberación y toma de decisiones para la elección de autoridades municipales en Oxchuc. En cumplimiento al Decreto 135 del Congreso del estado, fue convocada por el presidente del concejo municipal de Oxchuc.

El domingo 24 de febrero de 2019 se celebró la asamblea, con solo representantes de nueve localidades sin participar: Cruzaquilja, San Marcos, Cholol, Santa Teresa La Reforma, Tekmaxtik, Saklumilja, Jutuba, El Porvenir, Newitz y Chapultepec. Por lo anterior, quedó formalmente instalada la asamblea general, con la asistencia de representantes propietarios de 111 localidades de un total de 120 que integran el municipio. Cabe mencionar que dichos representantes fueron nombrados en las correspondientes asambleas comunitarias que se celebraron en cada localidad, del 13 al 19 de febrero de 2019.

Ese mismo día, cumpliendo con el principio de paridad, la asamblea general eligió, a través del método de mano alzada, a los integrantes de la mesa de debates, de la que quedó como presidente el representante de la comunidad Santísima Trinidad y una representante de Bumilja como suplente. La mesa de debates tiene como responsabilidad llevar el desarrollo de la asamblea general, procurar acuerdos entre los representantes, levantar las actas respectivas, ser el enlace entre el municipio y el IEPC, y notificar a este último del cumplimiento de cada una de las etapas del proceso de elección.

Durante el desarrollo de la asamblea general, por unanimidad manifestada a mano alzada, los representantes determinaron solicitar la coadyuvancia del IEPC en la elabo- 
ración de las reglas y, en su caso, la organización del proceso de elección. ${ }^{5} \mathrm{Al}$ tratarse de una asamblea permanente, se declaró un receso para regresar el próximo miércoles 27 de febrero, con el propósito de que los representantes informen a sus localidades correspondientes de los acuerdos tomados y elaboren las propuestas que deberán integrar las reglas para el proceso electivo que discutirá la asamblea general.

\section{Las reglas de la elección por sistemas normativos internos}

Las reglas del proceso electoral de Oxchuc fueron elaboradas por la asamblea general permanente. Se trata de un documento integrado por 40 normas, agrupadas en 11 temas, que armonizan reglas vigentes décadas atrás con derechos contemporáneos. La intención fue recuperar las buenas prácticas de su derecho electoral y actualizarlas en un nuevo catálogo de normas. De acuerdo con lo pactado, dichas propuestas fueron entregadas al IEPC el 19 de marzo del 2019, para su validación. Una vez revisadas, el 29 del mismo mes se emitió el Acuerdo del Consejo General del IEPC, por el que se validaron las normas que regirán la elección de las autoridades municipales del municipio de Oxchuc, conforme su sistema normativo interno.

El documento contiene dos secciones: una relativa a los acuerdos de las cinco asambleas celebradas por la asamblea general permanente, en ejercicio de su derecho al autogobierno y en razón al contenido de sus reglas electorales; y otra dirigida a las observaciones y sugerencias que el IEPC hizo a las mismas, en cumplimiento al Decreto 135 emitido por el Congreso del estado de Chiapas. Dentro de las nuevas reglas del sistema normativo electoral de Oxchuc destacan, entre otras, las relacionadas con los requisitos de elegibilidad, la creación de la comisión de mediación, la determinación de la figura de la autoridad municipal, el método de la lección, el respeto al principio de paridad, el modo honesto de vivir y la revocación de mandato.

En cuanto a la sección de requisitos de elegibilidad, se estableció la limitación a los aspirantes a los cargos de no pertenecer al mundo eclesiástico ni ser ministro de algún culto religioso en el municipio. Esta norma atiende el hecho de que más de la mitad de la población del municipio profesa hoy distintas religiones cristianas evangélicas, y que años atrás los conflictos religiosos se vivieron de manera muy violenta, con miles de expulsados en los municipios indígenas.

Se creó también una Comisión de Mediación y Resolución de Conflictos, que es probable intente cumplir con una de las funciones del gobierno indígena, que es la resolución de conflictos en procesos electorales buscando establecer mediaciones. Esta nueva comisión quedó integrada por cuatro miembros, y cumple con el principio de paridad de género: Dionisio Encinos Gómez como presidente, Rosa Morales López como secretaria, Daniel Gómez Santiz como primer vocal y Norma Araceli Santiz López como segunda vocal.

5. Araceli Burguete Cal y Mayor, «13 de abril de 2019, elecciones por usos y costumbres en Oxchuc: El calendario electoral», Chiapas Paralelo, 21 de maro de 2019, disponible en http://bit.ly/2QXzR5i. 
Un aspecto interesante fue la decisión de la asamblea de refrendar como su forma de gobierno municipal el ayuntamiento en los términos del artículo 115 de la Constitución Política Federal, puesto que la sociedad civil protagonizó una lucha por recuperar su sistema electoral propio en un marco del ejercicio del derecho de autodeterminación indígena, y no lo ejercitó respecto del diseño de un nuevo sistema de autoridades que propiciara un gobierno propio.

Lo anterior marca una diferencia crucial con los procesos ocurridos en Cherán, Michoacán y en Ayutla de los Libres, Guerrero, pues en estos municipios se establecieron concejos de gobierno que sustituyeron a los ayuntamientos; en Cherán se generó un concejo mayor de gobierno, mientras que Ayutla creó un concejo comunitario. Una razón de fondo para mantener al ayuntamiento quizá sea el diseño de las políticas fiscales y del sistema fiscal de las entidades federativas que privilegian esa forma de gobierno. A los concejos de gobierno indígena se les dificultan los procesos formales como las firmas de documentos oficiales, sobre todo los bancarios.

La fecha señalada para la elección fue el 13 de abril en asamblea general comunitaria única, que se celebró en la explanada de la cabecera municipal. La votación se emitió a mano alzada. Lo anterior requiere una logística compleja, pues el municipio registró una población total para el año 2018 de 35.780 personas. En esta tarea participaron las autoridades comunitarias para establecer las mesas de registro de sus integrantes, quienes presentaron su credencial de elector y canalizaron el ingreso de sus miembros de forma ordenada. De la misma manera, las policías comunitarias se encargaron de la seguridad de las elecciones.

Otra situación interesante es que en los requisitos de elegibilidad se cumplió el principio de paridad. La incorporación de las mujeres en todo el proceso es una de las principales innovaciones; sin embargo, se requiere lograr avances significativos, lo que implica modificar la organización social de todo el pueblo de Oxchuc.

Las dificultades que las mujeres enfrentan en Oxchuc para participar como candidatas es mayor. Por un lado están los usos y costumbres, relacionadas con el tema agrario. Por el otro, las relaciones de parentesco, aunado a que no son consideradas ciudadanas. De esto resulta que, en sentido estricto, las mujeres tengan dificultades para cumplir con un requisito de elegibilidad establecido en las nuevas normas electorales: para poder ser candidato se requiere que sea cooperante y que haya servido en la comunidad con servicios según su escalafón comunitario.

En otra sección se establece el principio de revocación del mandato a quien ejerce un cargo municipal, y que éste puede operar por observación libre en cualquier momento del mandato. Es decir, por vigilancia ciudadana. La asamblea decidió que el próximo presidente municipal y el resto de los integrantes del cabildo estén sujetos a la observación durante su administración respecto de las causas que se tomen como motivo de separación del cargo.

Cabe mencionar que la norma del modo honesto de vivir no se establece como una posible causa de revocación del mandato, pero quedó incorporada como un requisito de elegibilidad, por lo que ambos principios se cruzan en el derecho consue- 
tudinario electoral de Oxchuc con la intención de combatir la corrupción que pudiera presentarse.

Ahora bien, en cuanto al procedimiento, se estableció que la mesa de debates de la asamblea general sería la encargada de: i) emitir la convocatoria a las elecciones, con base en las normas validadas; ii) conducir la asamblea de elección desde su instalación hasta su clausura; iii) garantizar el libre acceso de la ciudadanía para emitir el voto; y iv) hacer constar el registro de los asistentes, verificar la votación y sus resultados.

Los candidatos a la presidencia municipal fueron postulados por los principales (autoridades tradicionales con prestigio público en Oxchuc) y validados por la asamblea general, que revisó el cumplimiento de los requisitos de elegibilidad. El resto de los cargos del ayuntamiento (síndico propietario y suplente y los seis regidores propietarios y suplentes) son originarios de 14 localidades diferentes, y fueron postulados por mayoría de los representantes de las 120 localidades del municipio de Oxchuc que integran la asamblea general.

Así, el 13 de abril en la explanada del Parque Central del municipio de Oxchuc se celebró la primera elección a través del sistema normativo indígena basado en los usos y costumbres en Chiapas, en la que participaron cerca de 12.000 ciudadanos de 115 localidades del municipio, quienes eligieron a sus autoridades a través del método de mano alzada en una asamblea general comunitaria única.

La elección inició a las ocho de la mañana, cuando la ciudadanía de Oxchuc se dio cita en la plaza principal de la cabecera municipal para iniciar con su registro. Para ello, presentaron su credencial de elector e ingresaron a la plaza pública. La mesa de debates fue la encargada de conducir la asamblea general comunitaria única desde su instalación hasta su clausura. Una vez instalada, se presentó a los candidatos a la presidencia municipal, quienes habían sido postulados previamente por los principales y validados por la asamblea general.

Acto seguido, se dio paso a la presentación de los candidatos a síndicos y regidores, respetando en todo momento el principio de paridad de género. De estas postulaciones, la candidata Patricia del Rosario López Gutiérrez también declinó, por ser vocal de la mesa de debates.

Luego, la mesa dio paso a la sanción de las candidaturas (votación a mano alzada). $\mathrm{Al}$ respecto, la asamblea general había determinado que no sería necesario el conteo individualizado de los votos si la votación fuera visible y marcadamente mayoritaria o de unanimidad. En caso contrario, la mesa de debates tomaría las decisiones necesarias para organizar a los asistentes y proceder al conteo de la votación con el auxilio de las autoridades de cada comunidad.

Ello no fue necesario, pues hubo una votación visiblemente mayoritaria a favor de un candidato, lo cual resultó relevante, pues el proceso electivo en una asamblea única con la utilización del método de mano alzada no rompe con los principios democráticos constitucionales de certeza y seguridad jurídica, en tanto sea posible determinar con precisión el sentido del voto de quienes se congregan a expresar su voluntad. 
Culminada la elección, la mesa de debates elaboró el acta de asamblea firmada por sus integrantes, en la que se acreditó el control de los asistentes, de los participantes, de la localidad de origen, de los incidentes, de la manera en que se celebró la votación, cómo se contaron los votos, quiénes fueron electos, el cumplimiento del principio de paridad en las candidaturas y el principio de paridad vertical en la integración del ayuntamiento.

A partir de esta información, en sesión extraordinaria el 22 de abril del 2019, el IEPC, según lo dispuesto en el artículo 2 de la Constitución Política de los Estados Unidos Mexicanos; el artículo 7 de la Constitución Política del Estado Libre y Soberano de Chiapas; y el artículo 1 del Decreto 135 del Congreso del estado de Chiapas, así como en cumplimiento al Acuerdo IEPC/CG-A/17/2019 emitido por ese cuerpo colegiado - toda vez que dicho proceso se apegó a las normas establecidas en la convocatoria, los candidatos electos obtuvieron la mayoría de votos y cumplieron con los requisitos de elegibilidad-, el consejero presidente Oswaldo Chacón Rojas entregó la constancia de mayoría y validez al presidente municipal Alfredo Santiz Gómez, así como a síndicos y regidores que integrarán el ayuntamiento.

\section{Reflexiones finales}

En México, solo mediante la judicialización de los sistemas normativos indígenas es posible ejercer el derecho a la libre determinación en materia política que la Constitución Política de los Estados Unidos Mexicanos reconoce a los pueblos originarios. Los conflictos políticos suscitados en Oxchuc, Chiapas en los últimos veinte años motivaron la promoción de varios juicios ante el TEPJF hasta que, mediante sentencia del TEECH, se ordenó respetar su derecho a elegir bajo sus propios sistemas normativos a sus autoridades municipales. En Oxchuc, la autoridad judicial electoral, al resolver un conflicto relacionado con el derecho a la autodeterminación, armonizó las normas electorales del Estado con los sistemas normativos internos, mediante criterios de modulación que generaron una especie de interlegalidad. El derecho electoral indígena y el sistema electoral hegemónico coexisten respetando los derechos humanos.

La intervención de la asamblea de Oxchuc se presentó desde la resolución del TEECH, en la que se ordenó consultar a la población respecto de su intención de celebrar una elección bajo sus sistemas normativos propios. En consecuencia, el IEPC intervino en diferentes momentos en la toma de decisiones de la asamblea que se integró en dicho municipio, con la finalidad de orientar en el marco de los derechos humanos $y$, desde luego, en cuanto a las reglas explícitas de preferencia en el sistema jurídico mexicano.

El tema central fue sin duda superar la idea de preponderancia del sistema electoral de partidos políticos, que incluye la imposición constitucional de utilizar y respetar de manera irrestricta su legislación electoral, ya sea federal o local, sobre los sistemas normativos indígenas de elección de autoridades. Todo ello, con el compromiso de respetar los derechos humanos. 
El primer aspecto que se pudo advertir fue la fecha de la toma de protesta del cargo del nuevo ayuntamiento. Se permitió que la toma se llevara a cabo un día después de la calificación de la elección, situación que hace presumir la cancelación del acceso a la justicia de los inconformes con el resultado; sin embargo, este derecho queda a salvo y puede tramitarse según los procedimientos electorales establecidos para los medios de impugnación por la Ley General de Instituciones y Procedimientos Electorales. La decisión de aceptar esa fecha se debe por un lado a los usos y costumbres de Oxchuc y a la necesidad de contar con la figura de poder, es decir, empoderar de inmediato a quien resulte electo, pues, al surgir de un proceso legítimo, urge que entre en funciones. En ese sentido, aparece una modulación respecto de los tiempos de tomar posesión en el cargo, ya que si bien puede encontrarse en funciones, el nuevo ayuntamiento no está exento del análisis jurídico de la elección.

La segunda situación analizada fue que se condicionara la participación en la elección a ser oriundo con residencia ininterrumpida en el municipio. El IEPC sugirió a la asamblea la salvedad en aquellos casos en que, habiéndose ausentado la persona, no haya perdido vínculo con la comunidad; a juicio de la propia asamblea, dicha observación se aceptó y se implementó en las reglas. La modulación se aprecia en permitir la participación política a todos los sectores de la población sin más restricción que el respeto a los derechos humanos.

Un tercer reto fue eliminar que se condicionara la participación en la elección a la necesidad de ser cooperante, una actividad tradicionalmente reservada para los hombres debido a que las mujeres no tienen reconocida personalidad jurídica ante la comunidad, por lo que no forman parte de las organizaciones sociales en las que se puede cooperar o hacer tareas que impliquen ese trabajo a favor de la comunidad. Atendiendo la observación del IEPC, la asamblea acordó establecer la salvedad del caso de las mujeres que estuvieran imposibilitadas de cumplir con esa condición. Esta modulación implicó el respeto a las reglas explícitas entre el derecho electoral indígena y el sistema electoral hegemónico.

Establecer la cabecera municipal como único lugar de votación podría suponer una restricción para la participación de ciertos sectores que viven en comunidades lejanas o que no estaban en condiciones físicas de trasladarse, como personas de la tercera edad o mujeres embarazadas. Sin embargo, se respetó la decisión de la asamblea, toda vez que ésta fue adoptada por representantes de las 120 comunidades.

Ahora bien, la propia asamblea de Oxchuc utilizó criterios de modulación en su toma de decisiones; por ejemplo, la creación de una Comisión de Mediación y Resolución de Conflictos, con la intención de resolver ellos mismos las controversias que pudieran suscitarse con motivo de la elección. Un ejemplo fueron los requisitos de elegibilidad de candidatos, en los que se estableció la limitación de no pertenecer al estado eclesiástico ni ser ministro de algún culto religioso en el municipio, regla que termina con la tendencia católica que históricamente tenían las asambleas. Hoy conviven en Oxchuc distintas religiones: cristianas, evangélicas, católica y musulmana. 
Otra cuestión interesante fue la decisión de la asamblea de refrendar como su forma de gobierno municipal el ayuntamiento en los términos del artículo 115 de la Constitución Política Federal, puesto que la sociedad civil protagonizó una lucha por recuperar su sistema electoral propio en un marco del ejercicio del derecho de autodeterminación indígena, y no lo ejercitó respecto del diseño de un nuevo sistema de autoridades que propiciara un gobierno propio. Quizá esto se deba a que ese modelo les ha funcionado.

En términos generales, las determinaciones de la asamblea general de Oxchuc no fueron excluyentes, porque permitieron la participación de todos los miembros de la comunidad con credencial de elector, es decir, hombres y mujeres mayores de 18 años. Las reglas tampoco restringieron la participación política de las mujeres, debido a que se respetó la postulación e integración paritaria en su vertiente vertical, lo cual se logró al integrar fórmulas del mismo género para propietarios y suplentes, cuidando la alternancia del género a partir del cargo de presidente municipal. Tampoco se rompió con los principios democráticos de certeza y seguridad jurídica al aplicarse los procesos electivos de asamblea única y bajo el método de mano alzada, en tanto que fue posible determinar con precisión el sentido del voto de la mayoría.

El desafío ahora es que el nuevo gobierno municipal de Oxchuc actúe de forma que este mecanismo de elección se constituya en un modelo a seguir por otros municipios indígenas de Chiapas y de México en general, sobre la base de una administración pública incluyente y con respeto a las diferencias. Si se garantiza lo anterior, es probable que el modelo de elección de Oxchuc se institucionalice o al menos se continúe el desarrollo de criterios de modulación constitucional como alternativas de pluralismo jurídico, en escenarios en que el desacuerdo político se genera no por la forma de gobierno, pues se decidió conservar la figura del ayuntamiento, sino por la corrupción que se vive en el sistema de partidos políticos que cada vez alejan más a la ciudadanía de la participación política.

\section{Referencias}

Gómez Muñoz, Maritza (2004). Tzeltales. Ciudad de México: CDI- PNUD.

Maldonado Alvarado, Benjamín (2013). "Comunalidad y responsabilidad autogestiva». Cuadernos del Sur: Revista de Ciencias Sociales, 18 (34): 21-28. Disponible en https://bit.ly/2TgPzLN.

SANTos, Boaventura de Souza (1987). «Law: A map of misreading. Toward a postmodern conception of Law». Journal of Law and Society, 14 (3): 279-302. DOI: 10.2307/1410186.

-. (2001). A crítica da razão indolente: Contra o desperdício da experiência. San Paulo: Cortez.

-. (2009). Pluralismo jurídico y las escalas del derecho: Lo local, lo nacional y lo global. Madrid: Trotta, ILSA.

Servicios del Pueblo Mixe (1995). Contribuciones a la discusión sobre derechos fundamentales de los pueblos indígenas. Oaxaca: Servicios del Pueblo Mixe. 
Yrigoyen FAJARDo, Raquel (1999). Pautas de coordinación entre el derecho indígena y el derecho estatal. Guatemala: Fundación Myrna Mack.

\section{Sobre el autor}

Manuel Gustavo Ocampo Muñoa es licenciado y maestro en Derecho por la Universidad Autónoma de Chiapas, México. Candidato a doctor por el Instituto de Investigaciones Jurídicas de la misma casa de estudios, en el cual es también profesor investigador nivel 1, con línea de investigación en la gobernabilidad democrática. Su correo electrónico es manuel.ocampo@iij-unach.mx. (D) https://orcid.org/oooo-0o02-4265-4761. 
